Gazi University
Journal of Science
http://dergipark.gov.tr/gujs

\title{
Fractal Dimension of Islamic Architecture: The Structure of the "Patkaneh" in the dome of the Jame' Mosque of Ardestan, Iran
}

\author{
Mahya GHOUCHANI ${ }^{1, *}$ (D), Mehdi MOKABERIAN ${ }^{2}$ (D) \\ ${ }^{1}$ Department of Architecture and Urban Planning, Technical and Vocational University (TVU), Tehran, Iran \\ ${ }^{2}$ Lecturer, Department of Architectural Conservation, Semnan Payame Noor University, Semnan, Iran
}

\section{Highlights}

- This research has been studied the "Patkaneh" srtucture in the dome system of mosque.

- The development of cornering (ChapireSazi) under the dome.

- This research has been compared the geometry of Patkaneh srtucture with the fractal geometry.

\begin{tabular}{l} 
Article Info \\
\hline Received: 13 Aug 2021 \\
Accepted: 29 Dec 2021 \\
Keywords \\
Fractal geometry \\
Islamic architecture \\
Patkaneh \\
ChapirehSazi \\
Dome structure
\end{tabular}

\section{INTRODUCTION}

The dome has been used in architecture for many years. During this time, these curved surfaces with various shapes are placed on different planes such as circle, octagon, and quadrilateral. As the number of sides of the shape used to be placed under the dome increases, the connection problem between the dome and its lower part is solved more easily. "So that in the circle, there is practically no problem to connect to the base of the dome. But in quadrilaterals, how to turn a cube into a dome is a vital matter for the dome to stand" [1]. How to turn a square or polygonal background into a circular design, to place the dome on it, has been one of the most important problems in building domes. "Based on the available evidence, the Iranians introduced this art to the world of architecture" [2]. The process of changing square into the circle in Iranian dome chambers and the how of this process is a problem that has created many architectural forms and techniques in the structure of domes' zone of transition over the centuries of trial and error.

One of the highlighted points of this evolutionary trend is the flow started with the formation of zone of transition of Khaje Nezam-al-molk dome of Isfahan Jameh mosque in the second half of the 5th century HA. "This elegant form of structure and geometry, as one of the most important achievements of the Seljuk era, has been as the dominant pattern of transitional zones in vast areas of Iran's plateau for centuries" [3]. "The geographic area of Esfahan is one of the most powerful Iranian architectural centers that has experienced architectural flourishing in the fourth and fifth centuries and created a style called "Seljuk"' [4]. The building of the Jame' Mosque of Ardestan is one of the most authentic Seljuk monuments; although it has obvious Seljuki characteristics such as brickworks and Kofic inscriptions in its structure of zone of

\footnotetext{
* Corresponding author, e-mail: m.ghouchani.arch@gmail.com
} 
transition, it presents a different solution to the common tradition influenced by the achievement of Nezamal-molk dome.

Corner construction of the dome to convert a square plan into a circular plan is called "ChapirehSazi".According to the original definition, "Petkaneh" [pǽtk^ne] is an organ consisting of several rows of ledges that are mounted on top of each other and come forward. "The development and evolution of this organ lead to the formation of one of the most interesting and complex Iranian arches" [5]. A review of different sources shows that there are no identical interpretations of the word "Patkaneh" and the boundaries of this traditional architectural component with similar examples are unclear. Sometimes the definitions are not comprehensive and are limited to a part of the examples. "In other cases, the proposed definition interferes with other techniques of cornering construction, arch and dome" [3].

Due to the nature of the Form-Structural and multiple functions of "Patkaneh", it seems that the study of this srtucture requires a comprehensive look. An attitude that considers both structural and formal considerations. The lack of such a view, among many studies, has led to the superficial or incomplete introduction of "Patkaneh". In the area of transferring the dome of the Jame' Mosque of Ardestan and how to turn a quadrilateral into a circle in this dome, initiatives have been used that have caused differences with the common method of cornering in Iranian architecture. In this method, the quadrilateral is not converted to an octagon, but the connection between the bowls is maintained throughout the ChapirehSazi. Information about the Jame' Mosque of Ardestan especially the dome of this mosque is limited to very general information and lacks the necessary accuracy, which shows the importance of addressing this issue.

The present study intends to answer the question of what is the structural system of the dome of the Jame' Mosque of Ardestan in the ChapirehSazi? And what are the differences between this method of execution and other Iranian architectural domes? The hypothesis of the present study is that despite some minor differences, the general form of the dome of the Jame' Mosque of Ardestan has been built following the architecture of Iranian domes. But in the ChapirehSazi, there are fundamental differences with the common methods in Iranian architecture. This structural difference is the same as the execution of the "Patkaneh". Therefore, the aim of the present study is to investigate the structural system of the dome of the Jame' Mosque of Ardestan, the cover of "Patkaneh" and how to implement it in the form of a systematic structural set. Finally, due to the structural similarity of the "Patkaneh" to the fractal, the shape geometry of this coating is compared with the fractal geometry.

\section{LITERATURE REVIEW}

\subsection{Architecture of The Jame' Mosque of Ardestan}

"After the advent of Islam, Iranian architecture entered new stages and after several centuries, the fundamental elements of Sassanid architecture culture followed in a new framework" [6]. The dome and porch were used in various buildings. Following this trend, the mosque was formed by adding these two elements to the columnar naves. These components together formed a continuous unit that became a common form for mosques and even schools and inns. "This method of construction not only dominated the architecture of Iran but also spread to other parts of the Islamic world, from Egypt and Anatolia in the west to Central Asia and India in the east" [7].

The Jame' Mosque of Ardestan is located in Ardestan city (in Isfahan, Iran). "This mosque, which was built during the Seljuki period, is the first two-story mosque in the history of Islam and the second four-porch mosque in the Islamic world" [8]. The Jame' Mosque of Ardestan, along with the bazaar and the school connected to it, with an area of about 340.85 square meters, includes several spaces. Architecture of the Jame' Mosque of Ardestan is shown in Figure 1. 

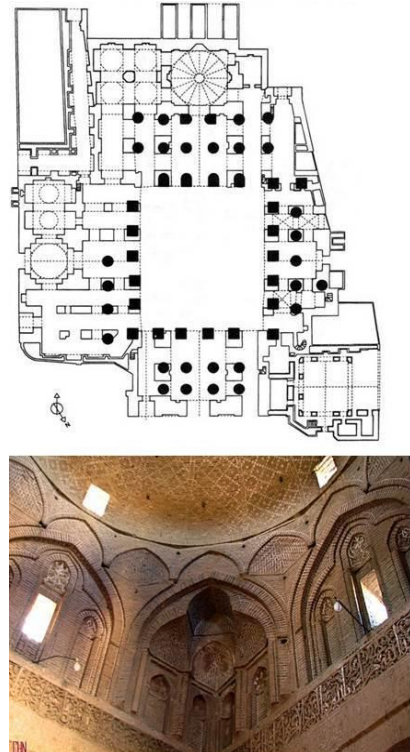

Figure 1. Plan, section and pictures of the Jame' Mosque of Ardestan [9]

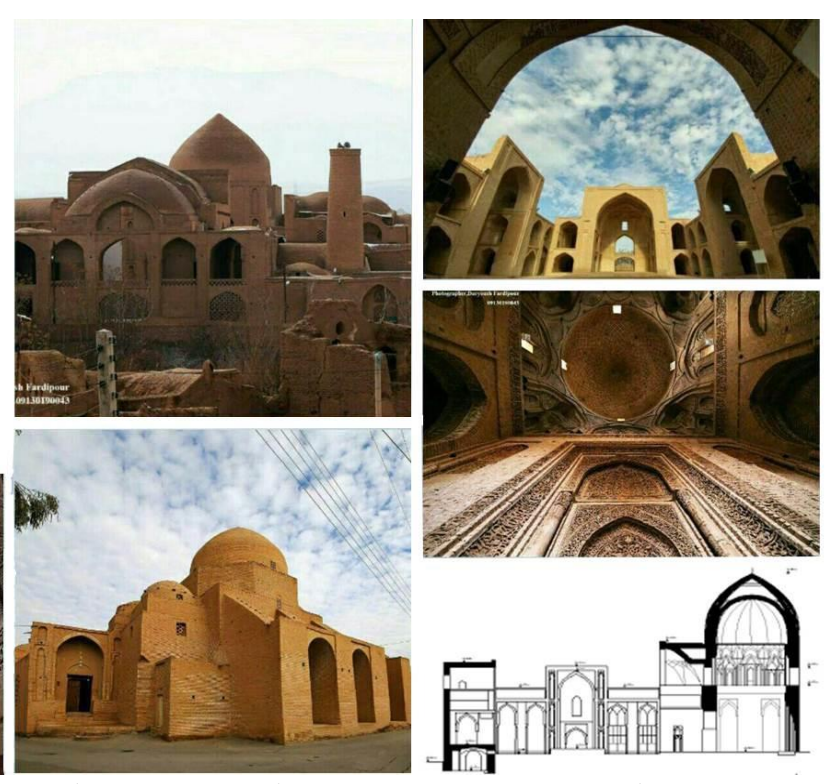
"The dome is located along the north-south axis and behind the main porch with a square plan measuring
9.33 with a height (floor distance to under the inner dome) of about 19 meters" [10]. Due to its dimensions, the dome became the main place of attention in terms of functionality, physicality and decoration. "The dome of this mosque is one of the beautiful examples of the dome of the Seljuki period, whose brick decorations are unique among similar buildings" [11]. This dome is located in the southernmost part of the mosque and is connected to the main nave of the mosque from the west.

"In general, the form of the dome consisted of three parts: a cube (base), a transition area and a curved arch roof on it" [12]. In the dome of this mosque, the base and the transfer area have been built very similarly, so that the distinction between these two parts needs to be more accurate. The base is divided into two parts, in the upper part of the base, like the lower part, there are two windows on each side with the role of lighting. But the south side does not have this type of windows due to the location of the altar. Therefore, in the outer and inner walls, instead of the window, an arch has been used so that the harmony between the walls of the dome is not lost. The transfer area, like the base, is divided into two parts. The division is in this way for more harmony between inside and outside. inside the dome of the Jame' Mosque of Ardestan is shown in Figure 2.

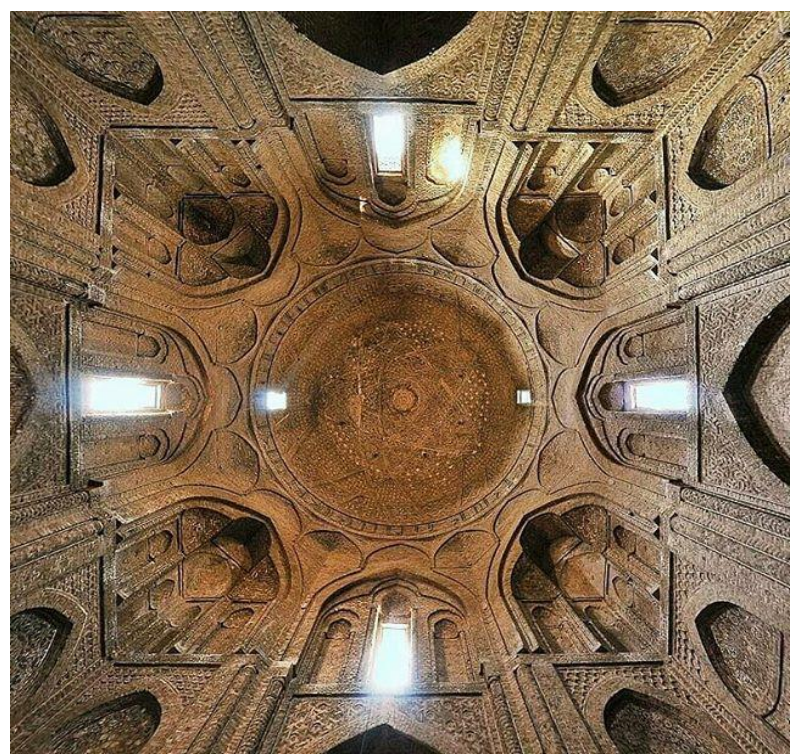

Figure 2. A picture from inside the dome of the Jame' Mosque of Ardestan and showing the transformation of a square plan into a circle 
Analysis and interpretation of the arches used in the dome of this mosque indicate that all the arches, including the arches of windows, entrances, and internal and external curves of the dome, follow the from one shape and their construction is based on one type of arch. By examining and matching the known arcs, the nearest arch, in terms of drawing, shape and historical range, is a three-part arch. "This arch is a subset of sharp arches that was built in the Dilamian period" [13]. The three-part arch, which is in the group of medium sharp arches, has a medium height. "This situation has caused this arch to be both load-bearing and to be used as a decorative arch" [14].

\subsection{Cornering in the Dome}

In many sources, the differences between "Patkaneh" and "Muqarnas" are not noticed and this structure (Patkaneh) is called "Muqarnas". For example, Liukak [15] "called the covering of the west porch of the Jame' Mosque of Isfahan (one of the most prominent examples of "Patkaneh" in world architecture), Muqarnas". Andre Godard also indirectly describes "Patkaneh". Referring to the examples of corner construction in the mosques of Isfahan and Barsian, he considers the Patkaneh ledges to be decorative. He believes that "since with the destruction of these ledges, the dome still remains, the transfer of cargo is done only through a few backs and the bowls are decorative" [16]. Accordingly, Godard does not consider the Patkaneh to be independent and introduces it as two separate structural limbs (arched strip behind the ledges) and decorative (ledges). On the other hand, Patkaneh is an independent arch or a corner structure that has its own shape and structural features.

The examination of sources shows that the most appropriate reference for the definition of "Patkaneh" is the definition of Pirnia in the article "Dome in Iranian Architecture" [17]. Accordingly, Pirnia considers "Patkaneh" as a kind of corner construction and provides a definition based on its construction method and morphology. "Several rows of ledges are stacked on top of each other to come forward to complete the corner composition. Patkaneh means a ledge on a ledge" [8]. He defines the boundary between "Petkaneh" and "Muqarnas" through differences in the method of execution and behavior of specific structures, and writes: At first glance, "Petkaneh" is very similar to "Muqarnas" and is mistaken for it. The main difference between the two is in the type of implementation. "Muqarnas" hangs from the ceiling. But "Patkaneh" stands on its own foot and does not hang. To make the "Patkaneh", they first make the lower ledges. Then the upper ledges will sit down on lower ledges. "But "Muqarnas" starts from the ceiling and gradually descends" [18].

"Typically, "Patkaneh" along with methods such as "Patkin", "Squinch" and "Philposh" is known as one of the methods of corner construction in Iranian architecture" [12]: "Squinch is one of the first examples of corner construction. It means to scratch. It is important to note that the loads on the dome are not transferred to these corners. For this reason, this type of corner construction does not affect the height of the dome. The performance of "Philposh" starts from zero point like a snail oyster and the arched layers overlap each other to reach the desired level. In fact, Philposh srtucture refers to the covering of the corner of the wall that starts from the corner and is placed between two intersecting walls. A kind of cornering construction that means gradually advancing the wall. "Patkin" has also been used instead of the "balcony". In this type of cornering construction, the horizontal rows of bricks are pushed forward in each row so that it can be seen from below as a step by step". Types of corner construction in Iranian architecture is shown in Figure 3. 

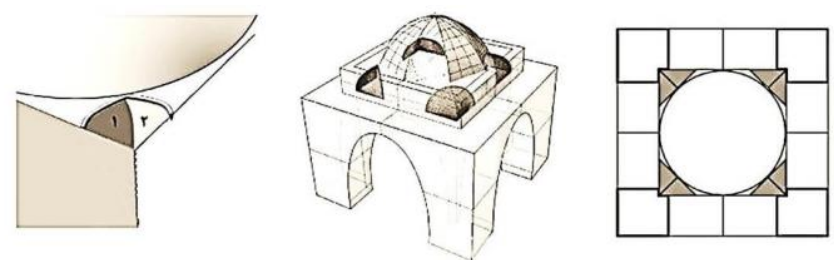

Squinch
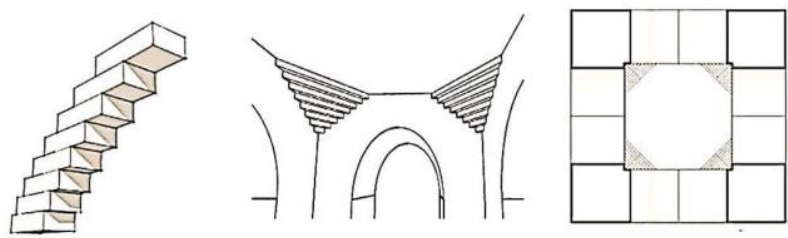

Patkin
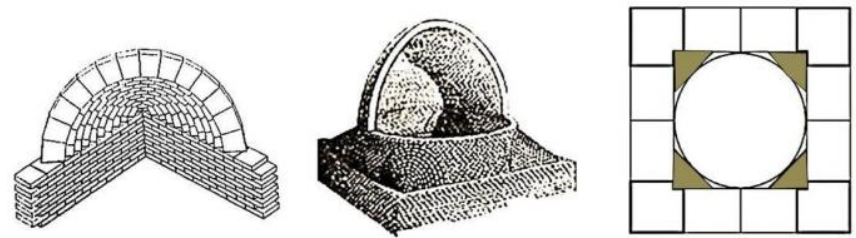

Philposh

Figure 3. Types of corner construction in Iranian architecture

"Patkin's corner construction is more similar to "Patkaneh". "Patkin" is one of the first solutions used in pre-Islamic architecture in Iran to corner the dome" [19]. Prototypes of this technology are wooden, the oldest of which can be seen in the fire temple "Bazeh Hoor" (Temple of the Sassanid period in Mashhad). "Pirnia introduces "Petkin" as a kind of corner construction which the French call Encrobellement and means the gradual advancement of the wall" [8]. In this method, by placing a brick in the corners, the square opening is brought closer to the circle; Thus, both "Patkaneh" and "Patkin" technologies are based on the idea of gradual advancement. In "Patkaneh", this is done using curved bowls, and in "Patkin", it is done by orthogonal stairs. The difference between how to execute Patkin and Patkaneh is shown in Figure 4.
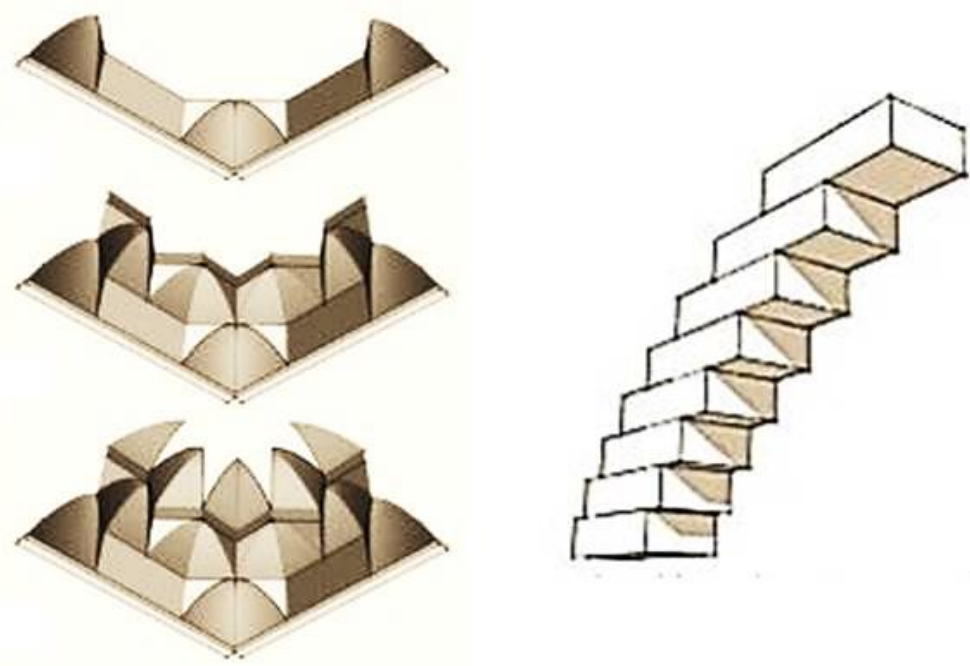

Figure 4. The difference between how to execute Patkin (right) and Patkaneh (left)

\subsection{Fractal Geometry in the Structural Form of Architecture}

As a novel view in the real geometry of nature proposed by French mathematician Benoit Mandelbrot, fractal science studies the geometrical aspects of natural structures. "In his theory, Mandelbrot explained that the universe has fractal dimensions and natural structures have fractal properties" [20]. His idea in mathematics states that nature follows nonlinear geometry and fractal rules to create various shapes. With respect to self-similarity and self-organization properties in fractals, it can be proposed that fractal geometry is a novel paradigm whose greatest potential is the ability to create form-based structures. 
The systemic method is one of the most comprehensive attitudes in applying nature's geometry and fractals in architecture. In this rationale, the properties of fractal geometry are examined in a correlation-based system to understand the process of development, evolution, and the principles governing this geometry. The main purpose is to recognize the laws of nature and to utilize fractal geometry strategies in architecture structure and form. In this regard, fractal properties examined in three fundamental subsystems: 1 . The structural system with an emphasis on sustainability aspects, 2 . The functional system with an emphasis on structural aspects and 3 . The physical system emphasizing the unifying aspects of components. Fractal structure is shown in Figure 5.

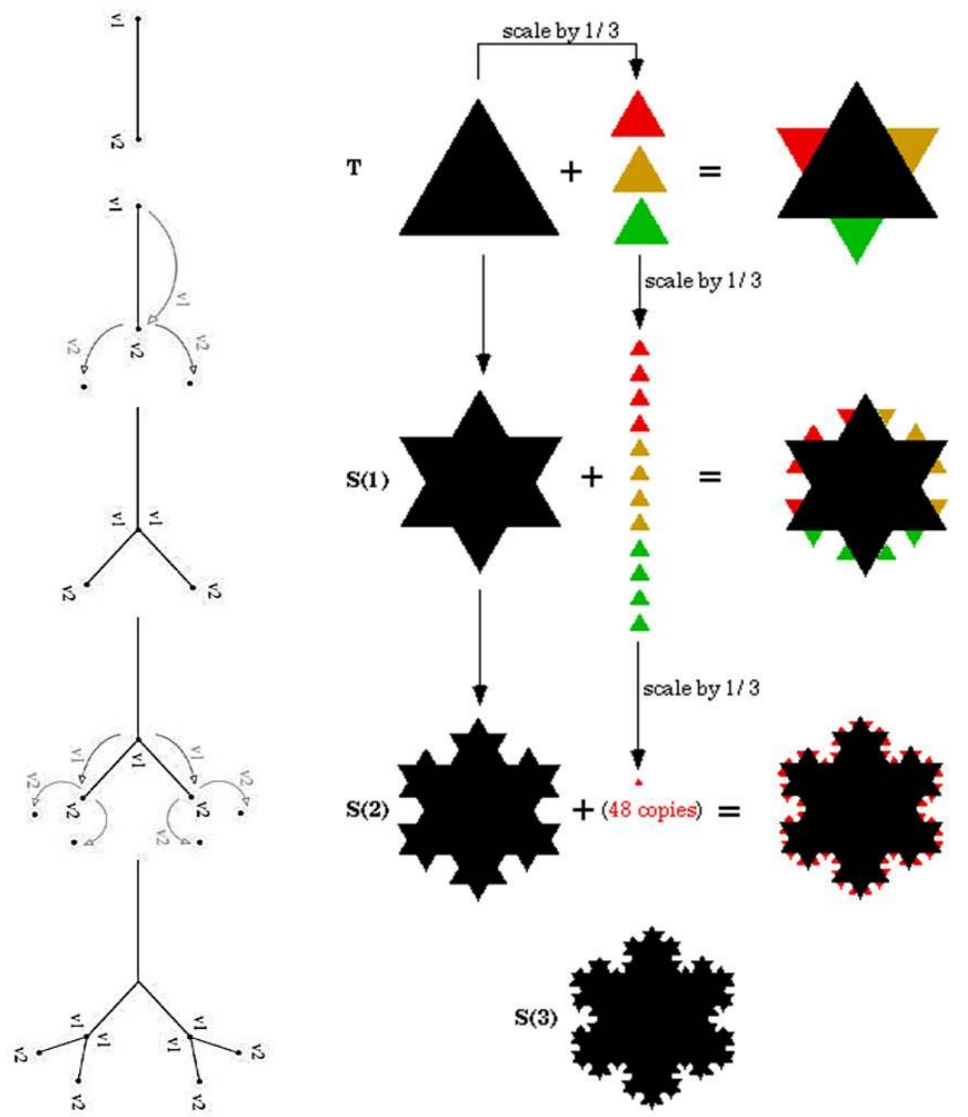

Figure 5. Construction of a tree-like fractal figure using vector-based recursion method [21]

- The structural system: The structural system consists of the firmness actions in the structure of nature. "This level of harmony between form and structure is required to achieve sustainability goals" [22]. The principles of "connectivity" and "branching" are important elements of the structural system. In the principle of connection, nature uses a mediator element to create connections for the best response to the structural system in the next step. "In branching or mutation, a more transcendental manifestation of intelligence and purposefulness takes shape through an evolutionary process" [22]. The universe is productive and evolving, "always creating variable goals and exposed to a distinguished momentary quality" [23]. "As Jencks notes, the mutable, momentary, and nonlinear orders introduce a new narrative in architecture based on fractal forms that accompany self-similarity in structure" [24]. This system refers to the principle of "self-similarity" in fractals.

- The functional system: "Each tree finds the shape of trunk and branches in resistance to environmental forces and is sustain to compressive and tensile forces" [22] so instead of a straight line, it curves to coordinate its form and function in an organized way. The principles of "continuity" and "consistency" are essential for a functional system, and create an interaction which is necessary for establishing hierarchical connections. In the principle of continuity, nature, with a sequence of similar elements creates rhythm in the process of evolution to respond to the structural organizing system in the best way. "The new patterns of order are consistent with selforganization and the regenerating evolutionary processes" [23]. In the 
principle of consistency, nature uses functions of nonlinear geometry as parabolas and hyperbolas to make structural connections. This system refers to the principle of "self-organization" in fractals.

- The physical system: "Natural systems have a property of unity in diversity, in the sense that multiple, diverse elements collaborate to exhibit a form of unity" [22]. The principle of "harmony and unity" is an important nature of the physical system, in which natural structures in harmony move toward unity and reoriginate from this unity. "In examining patterns of nature's geometry, Mandelbrot points out the important principle of homogeneous repetition from component to whole, in that the whole is very similar to the component, and each set of components is made up of the whole" [20]. This system refers to the principle of "unity" in fractals.

\section{RESEARCH METHOD}

The research method is descriptive-analytical and applied in terms of purpose. The initial information has been collected through direct field observations, interviews with masters of building restoration and library studies. First, the general form and architectural features of the Jame' Mosque of Ardestan are described and then the ChapirehSazi in the dome of this mosque is provided separately. "Because the srtucture of "Patkaneh" in the corner construction of this mosque is one of the best historical examples of the use of this srtucture" [10]. In order to avoid overstatement, addressing the aesthetic issue of the dome of this mosque has been omitted. Architectural images and plans are based on available documents. But its ChapirehSazi is harvested for the first time.

For this purpose, various information was collected on how to build the dome, the types of Corner construction and how to turn a square plan into a circle in the dome. This information was analyzed by field observations of the Jame' Mosque of Ardestan and compared with the information obtained from conversations with masters of building restoration. Then, to better understand and study the data, the geometric system of the dome and the ChapirehSazi of this mosque modeled with software such as AutoCAD and 3D Max.

\section{RESULTS}

Iranian architects have created several solutions for ChapirehSazi. Andre Godard classifies Iranian corner construction into two categories: "corner construction of "Philposh" for Sassanid domes and corner construction of arching used in Islamic domes" [2]. In addition to him, Pirnia [8] "has expressed a different classification" (this classification was explained in the introduction of the study). In this research, in order to classify the ChapirehSazi of the dome of the Jame' Mosque of Ardestan, the structural-form method of the book "Iranian Architecture: Niaresh" [25] is used, in which both the structure and the shape of the dome is studied simultaneously.

"According to this view, ChapirehSazi is divided into three categories: "without arching in the corner", "with arching in the corner" and "Karbandi"" [26]. The important point in the category "with arches in the corner" is the placement of 8 arches on the dome cube, which turns a quadrilateral into a regular octagon. "This technique became the main model in the ChapirehSazi of the dome after Islam in Iran" [27]. In the later stages, this shape becomes 16-sided, 32, etc. and finally becomes the base circle of the dome. How to place 8 arches on the dome cube in the ChapirehSazi is shown in Figure 6. 

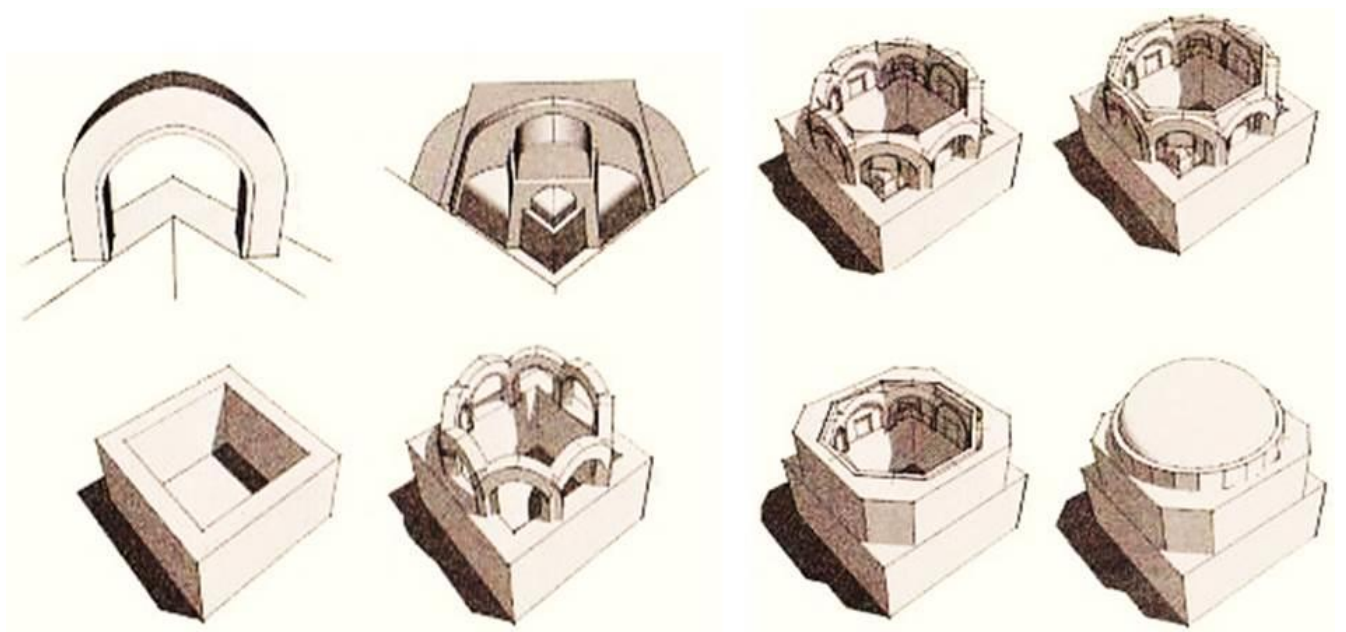

Figure 6. How to place 8 arches on the dome cube in the ChapirehSazi

"As mentioned in the introduction of the research, there were various methods such as "Patkin", "Patkaneh", "Squinch" and "Philposh" to fill the space between the eight arches" [12]. In the dome of the Jame' Mosque of Ardestan, the "Patkaneh" method has been used. In formal-structural Patkaneh, bowls are filling plates that rest on a strip of load-bearing arches. "But in formal Patkaneh, the bowls are decorative and are hung on another structure" [13]. Formal Patkaneh specimens act in structures such as Mogharnas. "But the group of formal-structural Patkaneh, apart from following the geometric pattern of Patkaneh, also has a structural role and the applied forces on the other hand carry the components and the gravitational force resulting from their weight" [17].

In the dome of the Jame' Mosque of Ardestan, the ChapirehSazi is made of three rows of bowls. The two rows of bowls are separated by windows located on the sides tangential to the dome. In the bottom row of each corner, there are 3 bowls with larger dimensions than the other bowls. The bowl, which is between the other two bowls, is divided into three parts by changing the surface in the middle section. The lower part of this segment has become a small bowl and acts like a "Squinch" to be placed in the corner of the "base" cube. In the upper row, there are two medium-sized bowls on the three lower bowls. The third row of bowls revolves around the dome and they are flat and curved one by one. The number of these bowls is 24 , which are smaller than all other bowls. On them, the base of the dome is placed, which has been turned into a circle on 24 edges. The space between the window and the bottom two rows of bowls is filled with flat plates. Since it covers a layer of brick ornaments on the ChapirehSazi, it is not possible to see the molding of the arches and other existing bowls. ChapirehSazi in the dome of the Jame' Mosque of Ardestan is shown in Figure 7.

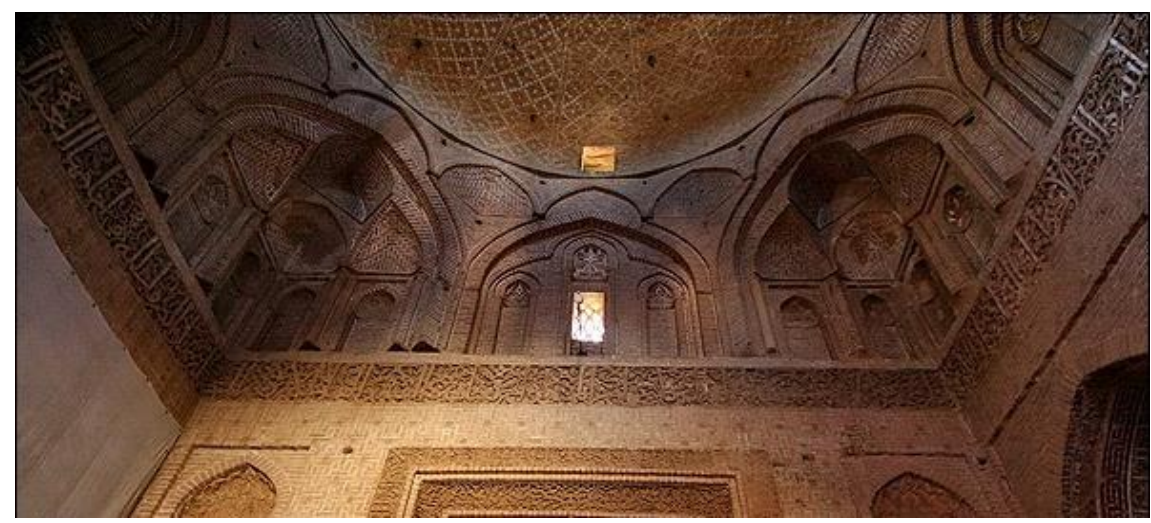

Figure 7. ChapirehSazi in the dome of the Jame' Mosque of Ardestan

The type of arrangement of the bowls and how to convert a quadrilateral to 24 edges one raises questions about the type of ChapirehSazi of this building. In the Islamic era, by building 8 arches based on the dome, they turned it into an octagon, then into 16 edges and finally into a circle. But in the case of the building 
under study, due to the layer of brick ornaments, the eight arches are not visible. However, the approximate location of these arches can be estimated from the plan and section of ChapirehSazi. If like other domes, we assume 8 arches at their designated points, due to the placement of the bowls, these hypothetical arches protrude from the ChapirehSazi and are not placed behind the bowls. The place hypothetical eight arches in ChapirehSazi is shown in Figure 8.

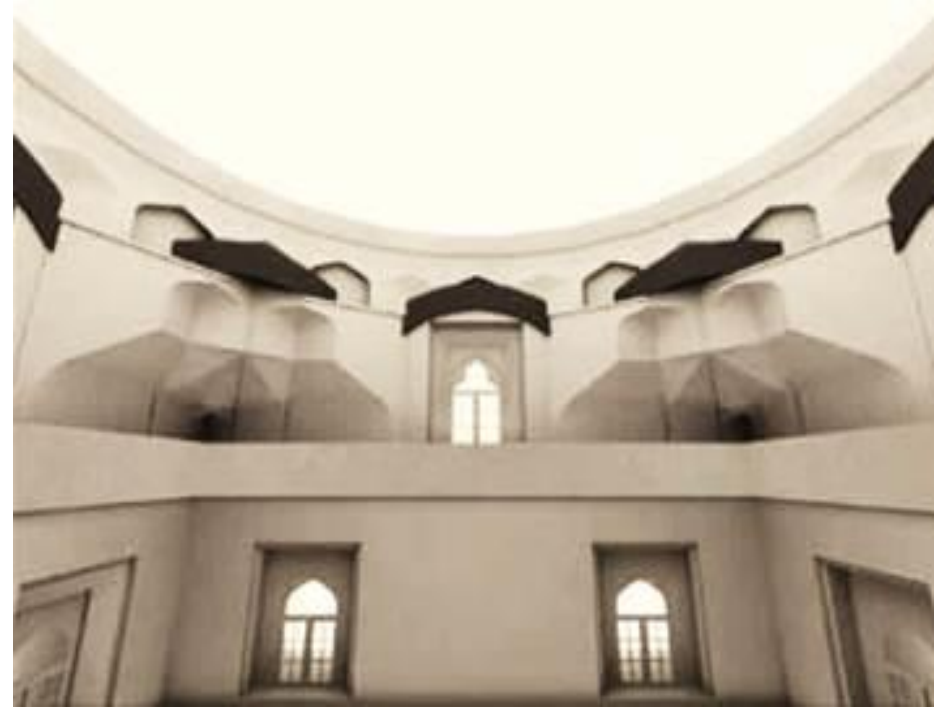

Figure 8. The place hypothetical eight arches in ChapirehSazi [27]

Another point that makes this position of the arch impossible for the dome of the Jame' Mosque of Ardestan is the angle of the establishment of the plates adjacent to the windows relative to each other. These plates, unlike the general method of corner construction in Iran, are not parallel to each other and they cut each other off. This prevents the hypothetical arch from being placed on a plate to remain hidden under the bowls and loses its bearing capacity. Because each of the two bases arches is not in the same direction. Therefore, the weight applied to them deflects the arch to the sides and loses its balance. Therefore, it seems that the method of placing the arches has been done in a different way. One point that can help confirm this is the presence of a space between windows and adjacent panels that confirms the placement of a bowl in that location. The location of the flat bowl in the corner of the wall is shown in Figure 9.

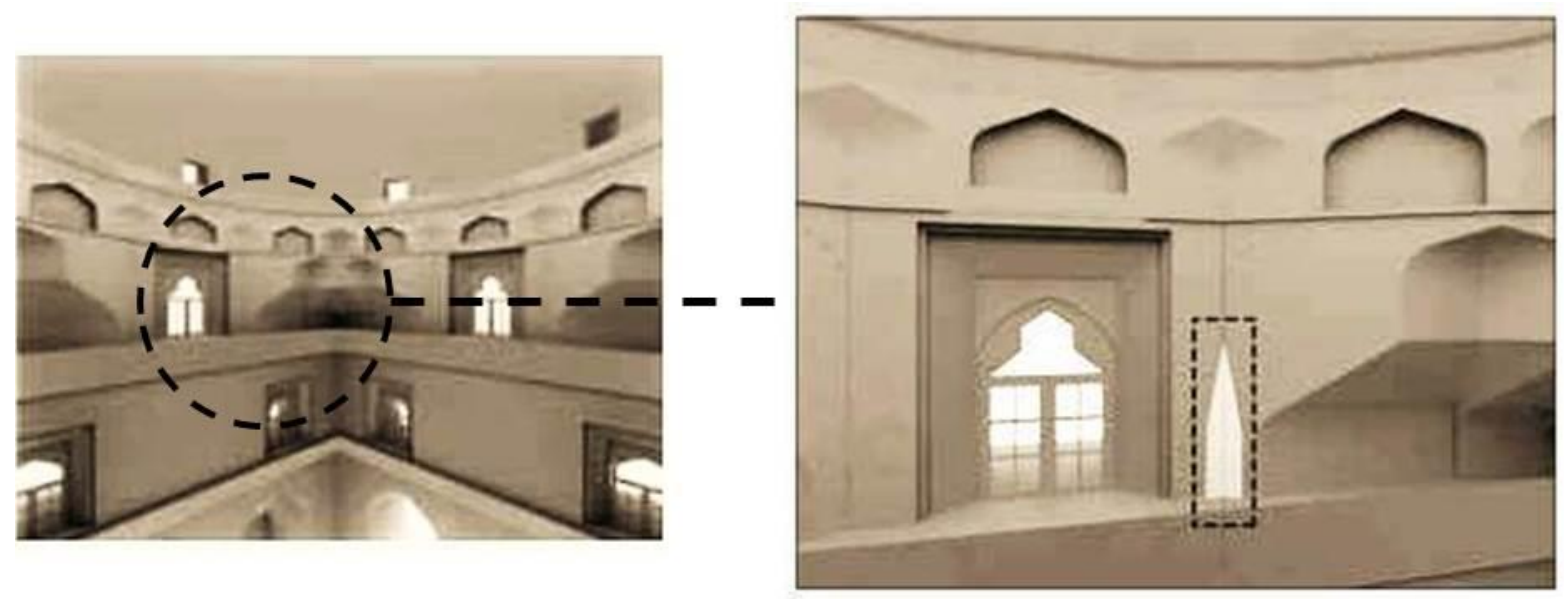

Figure 9. The location of the flat bowl in the corner of the wall [27]

With these documents, a model for the position of the arches can be designed. Like other domes, 4 arches are located in the middle of the sides, but in the corners of the base, instead of a sloping arch, 3 arches have been used. Based on the logical reasoning of the structural principles, it seems that two intersecting arches (one base of each of which is parallel to one of the adjacent plate of the windows) are located in the corner 
and each third arch base is located on the sharp point of the lower arch. Model of arches and Patkaneh cover in the dome of the Jame' Mosque of Ardestan is shown in Figure 10.
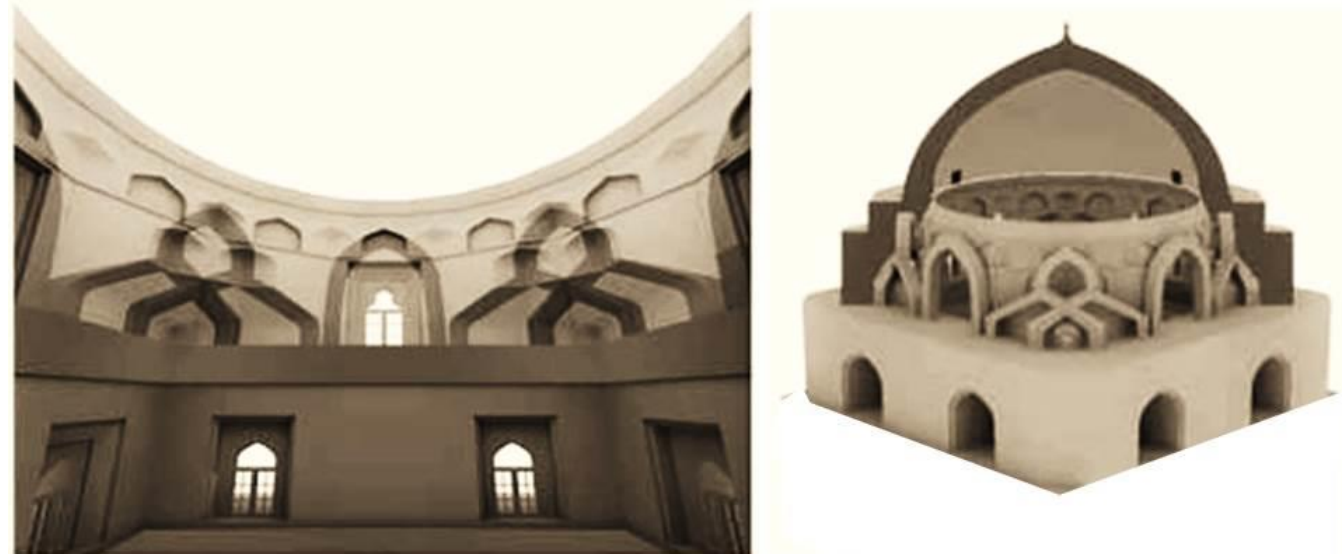

Figure 10. Model of arches and Patkaneh cover in the dome of the Jame' Mosque of Ardestan [27]

Based on the performed analyzes, it is possible to know the distinguishing features of Patkaneh srtucture with other srtuctures in the way of connecting its structure and form elements. The geometry of the Patkaneh is determined by the interaction between the geometry of the repeating arches on the roof and the geometry of the ascending bowls. This subject in other types of arches is based solely on the structural requirements. So this shape of the arches in terms of form and structure can be the answer to the dome construction.

\section{DISCUSS}

Self-similarity in fractals (the structural system) and "Patkaneh": The law of self-similarity in fractal creates a dynamic "rotation" with "transformation" in the geometrical nature of the main elements, and the structure is strengthened as it changes in dimensions and form. Subject to the mathematical laws of nature's geometry, such interactions create "conjunction" and "branches" to generate self-similar structure. "According to the law of self-similarity, a fractal produces self-similar structures in different levels to establish a hierarchy of connections in the next stage" [28].

In formal-structural Patkaneh, bowls are usually combined based on a common geometry. This geometry is obtained by breaking the right triangle created in the four corners of the square plan of the dome. Thus, each triangle is divided into two equal triangles. Then, by dividing the two sides corresponding to the walls into two equal parts and connecting the middle points to each other, four triangles and two squares are created, the squares themselves are divided into two triangles. The formation of these triangles in this way is the same as the law of self-similarity in fractals. The process of dividing bowls in Patkaneh is shown in Figure 11.
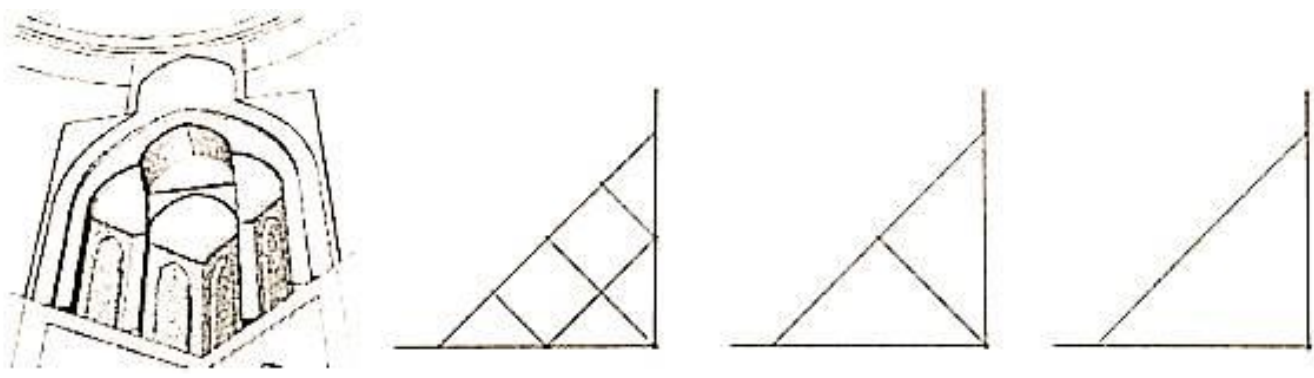

Figure 11. The process of dividing bowls in Patkaneh

Unity in fractals (the physical system) and "Patkaneh": The law of unity composes the main elements of a fractal structure into a comprehensive pattern and arranges hierarchal of connections in a way that different structural elements are unified. According to the law of unity, fractal structures exhibit unity moving forward and re-originating. The comprehensive pattern is derived from mathematical proportions 
of the natural geometry that has its root in the Latin word "pattern", which originated from the word "father" and indicates the oneness. "In creating structure, nature follows a comprehensive geometry pattern to maintain its continuity with the overall structure, thereby defining one identity" [22].

Considering the above, it can be said that the ChapirehSazi of the dome of the Jame' Mosque of Ardestan consists of 3 rows of 24 bowls (in some parts of the bowls have been removed or hidden). In such a way that the base is divided into 24 parts due to the extension of the radii of its surrounded circle. Then the 24 sections move forward to reach the base circle of the dome, depending on the location and space required. This is repeated in three steps until the size of all the bowls is equal in the last step. According to this placement process, In the first row, there should be 3 bowls between the bowls in the corners of one side. Also, in the second row, there should be 4 bowls between the corner bowls. Therefore, this forward motion creates the necessary unity for the stability of the structure, which is similar to the principle of unity in fractals. The process of arranging the bowls in the rows of shaping Patkaneh is shown in Figure 12.
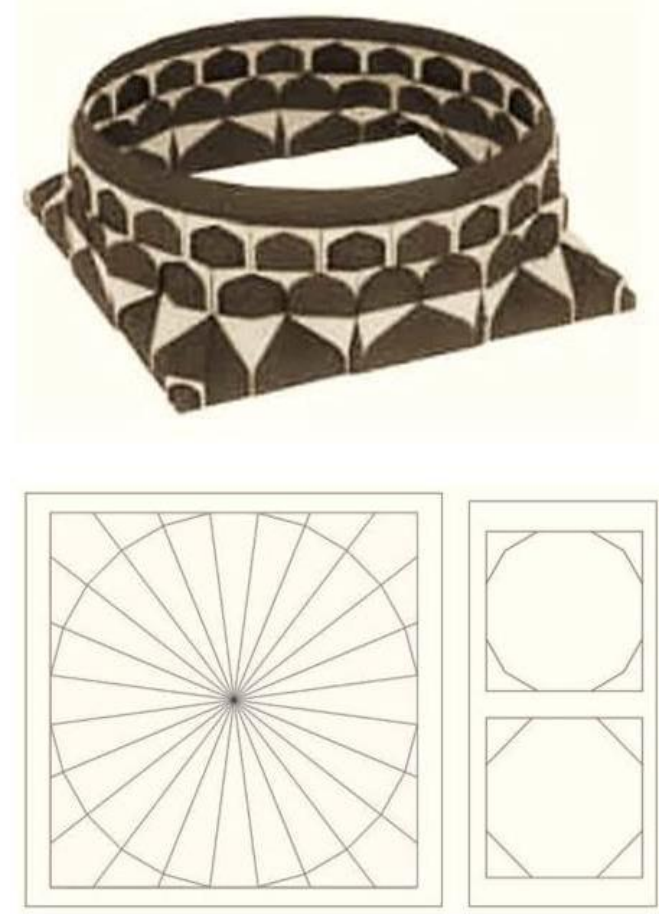

Figure 12. The process of arranging the bowls in the rows of shaping Patkaneh [27]

Self-organization in fractals (the functional system) and "Patkaneh": The law of self-organization in fractals creates the "hierarchy of connections" through nonlinear geometry properties of parabolas and hyperbolas, and the structure evolves and details into "geometric progressions". "In the law of selforganization, continuity, consistency, and rhythm are important characteristics in the hierarchy of connections created in the fractal structure" [21].

The arrangement of the bowls is such that the two lower heads of each bowl are on the upper heads of the two lower bowls. This method creates better propagation and expansion properties for the bowls. If in a closed space such as a cone, several rows of bowls are stacked on top of each other (with this arrangement), the number of bowls in each row is always equal to the other rows and only the size of the bowls changes. Another important point is that some bowls were made flat. These bowls, due to the wall in which they are placed, are two-dimensional and flat, and only the shape of their arch is visible. The hierarchy of connections for the arrangement of bowls is similar to the principle of self-organization in fractals. The hierarchy of connections for the arrangement of bowls is shown in Figure 13. 


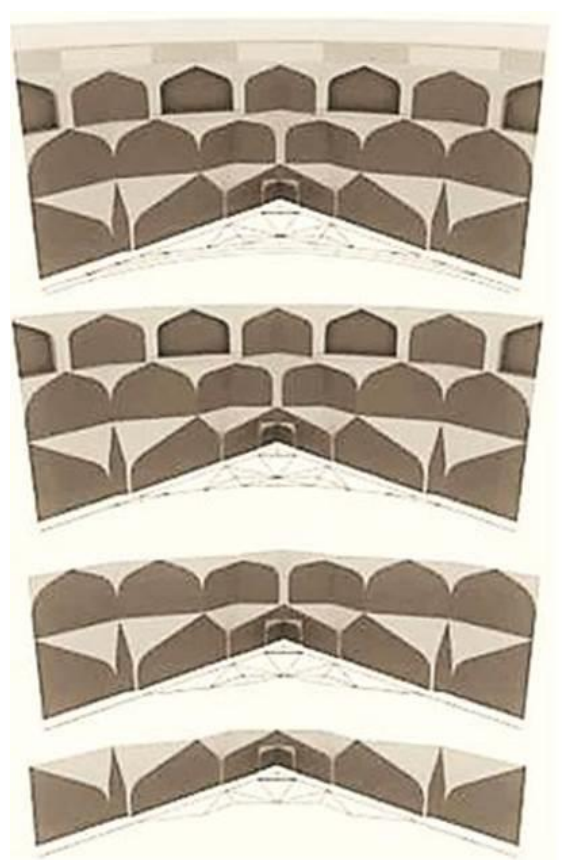

Figure 13. The hierarchy of connections for the arrangement of bowls [27]

According to the content provided, the process of using fractal geometry in Patkaneh is mainly accompanied by the application of the laws of self-similarity, self-organization, and unity, which create fractal quality in the architecture of Patkaneh.

\section{CONCLUSION}

The main issue in this study was to recognize the structure of the "Patkaneh" based on the case sample analysis. Based on the analysis of the findings obtained from field studies and three-dimensional modeling of the dome of Ardestan Grand Mosque, Petkaneh can be defined as follows: "Petkaneh" consists of several rows of bowls (shape aspect) that are placed on top of each other and come forward based on a regular and specific geometry, relying on bearing arches crosswise (structural aspect). This geometry is derived from fractal geometry in the form of similar and self-organized structures.

he high bearing of the arches causes these elements to be combined with the "Squinch" of corner construction technique, creating a combination of arched beams covered with bowls. Then, the above idea is repeated on all four sides of the opening, and with the emergence of "Corner construction of Squinch with bearing arches crosswise", the problem of corner construction is solved with better efficiency and more complete geometry. Finally, the regular combination of the arches on top of each other, creates stepped spaces under the structure. This causes the bowls to expand horizontally and vertically. In this case, the corner construction area penetrates to the dome area and merges in it and acquires a new and integrated structure. This new structure, which is the result of the development of corner construction of the entire space under the dome, can be called "Patkaneh" structure.

According to this definition, the independence of the form element (bowl) and the structural element (arch) causes the Patkaneh structure to have a significant variation in geometry and formation compared to other similar structures. This is done by using bearing arches crosswise, which is one of the distinguishing features of Patkaneh structure from other coatings. The law of self-similarity establishes the structural elements of Patkaneh's architecture, and the law of self-organization arranges the hierarchy of connections, while the law of unity integrates the structure of the Patkaneh's architectural form. In addition, form-based fractal architecture establishes a precise relationship between the composition of elements, structural requirements, and aesthetic concepts of ornamentation through the dual expression of structure and form, to provide internal correlation and external unity between constituent elements and Patkaneh's architectural form. 
It is necessary to emphasize that this article has examined the srtucture of "Patkaneh" in the dome of the Jame' Mosque of Ardestan. Providing a more complete definition of this srtucture requires research on the analysis of the geometric system, structure, and function of this srtucture in other developed examples. This research can be the beginning of more focus on civil engineering researchers on the importance of using "Patkaneh" in corner construction so that this structure can be subjected to structural tests and modeling and determine how to transfer load in this structure. Then this technique can be used in contemporary structures

\section{CONFLICTS OF INTEREST}

No conflict of interest was declared by the authors.

\section{REFERENCES}

[1] Rezazadeh Ardebili, M., Seyedi Saravi, M., Taheri Amiri, S., "A comparative study of the plan and dome of Ardabil Mosque with similar plans and domes to investigate the correct drawing of the dome curve", Journal of Fine Arts, 23(3): 69-82, (2018).

[2] Memarian, G., Soltanahmadi, B., Azarnoush, M., "New Theory about the First Chapire with Squinch Rip in Iran's Architecture History”, Journal of Iranian Architecture \& Urbanism, 8(2): 75-84, (2017).

[3] Golchin, H., Salehi kakhki, A., Jabalameli, A., "Explanation of Geometrical System of zone of transition in Gonbad-e Sorkh in Comparison with Common Pattern of Seljuk's Zone of Transition", The Monthly Scientific Journal of Bagh-e Nazar, 14(57): 75-84, (2018).

[4] Nasri, E., Aslani, H., "Study of decorative elements and architecture of the minarets of the Seljuk period in Isfahan", Peykareh, 9(20): 24-36, (2020).

[5] Zomorshidi, H., "Dome and Elements of Iran Arch", Second Edition, Tehran: Zaman Publications, (2011).

[6] Pope, A., "Iranian Architecture", Translated by Gholam Hossein Sadri Afshar, Tenth Edition, Tehran: Noghteh Publications, (2019).

[7] Hashemi, S. Y., "Introduction to Islamic Architecture", First Edition, Tehran: Sanei Publications, (2015).

[8] Pirnia, M. K., "Stylistics of Iranian Architecture", Tenth Edition, Tehran: Memarian Publishing, (2019).

[9] Taji, M., “Altar to Ascension; Principles of Mosque Design”, First edition, Tehran: Islamic Azad University, (2019).

[10] Salehi Kakhki, A., Azizpour, Sh., Rahimi Ariaei, A., Bank, F., "Analysis of the spatial-physical structure of Ardestan Grand Mosque with the separation of historical layers", Iranian Journal of Restoration and Architecture, 4(8): 33-46, (2014).

[11] Memarian, G. H., "Iranian architecture; Niarash", Eighth edition, Tehran: Goljam Publications, (2018).

[12] Golabchi, M., Javani Dizaji, A., “Architectural Technology of Iran”, Third Edition, Tehran: University of Tehran Press, (2016). 
[13] Vafamehr, M., "Technology of Traditional Iranian Architectural Structures", Third Edition, Tehran: Padideh Publications, (2015).

[14] Zomorshidi, H., "Iranian Architecture; Execution of a building with traditional materials", Second Edition, Tehran: Emerald Publications, (2016).

[15] Liukak, R., "Architects; Masters and builders in the architecture of the Islamic world (history and its social meaning)", Translated by Yaghoub Azhand, First Edition, Tehran: Molly Publications, (2009).

[16] Godard, A., Godard, I., "Arches and Arches in Iranian Architecture", Translated by Hamid Qaraguzlu and Saeed Saemi, First Edition, Tehran: Modiran-e Emrooz Publications, (2011).

[17] Safaeipour, H., Memarian, G. H., Bemanian, M. R., "Understanding what a hammer coating is through the analysis of the first examples in Iranian architecture", Iranian Journal of Architectural Studies, 5: 5-19, (2014).

[18] Hillenbrand, R., "Islamic Art and Architecture", Translated by Ardeshir Ishraqi, Second Edition, Tehran: Rozaneh Publications, (2012).

[19] Mohammadi, M., Neyestani, J., Mousavi Koohpar, S. M., "A study of typology, elements and components of Iranian architecture in the Sassanid period", Journal of Archaeological Research, 1(1): 83- 104, (2011).

[20] Mandelbrot, B., "The Fractal Geometry of Nature”, First Edition, New York, US: W.H. Freeman, (1983).

[21] MdRian, I., Shuichi Asayama, M., "From fractal geometry to architecture: Designing a grid-shelllike structure using the Takagi-Landsberg surface", Computer-Aided Design, 98: 40-53, (2018).

[22] Noghrekar, A. H., "Man's Relationship with Nature and Architecture”, First Edition, Tehran, Iran: University of Science and Technology, (2013).

[23] Taghvaei, V., "From Order to Disorder in Nature and Architecture", Hoviatshahr, 6(11): 39-52, (2012).

[24] Jencks, C., "The Story of Post-Modernism: Five Decades of the Ironic, Iconic and Critical in Architecture", First Edition, UK: Wiley, (2011).

[25] Memarian, G. H., "Introduction to Islamic Architecture of Iran", Tenth Edition, Tehran: Memarian Publishing, (2018).

[26] Rezazadeh Ardebili, M., "Restoration of Architectural Works", Eighth Edition, Tehran: University of Tehran Press, (2016).

[27] Abbaszadeh, M., Tarighi, S., Alizadegan, A., "The system of structures of the dome of the Urmia Grand Mosque", Safa Magazine, 28(83): 119-136, (2018).

[28] Mustaghani, A., Alimoradi, M., "Analysis of the application of nature and fractal geometry in parametric architecture by examining the internal array of the dome of Sheikh Lotfollah Mosque", Letter of Architecture and Urban Planning, 16: 103-121, (2016). 